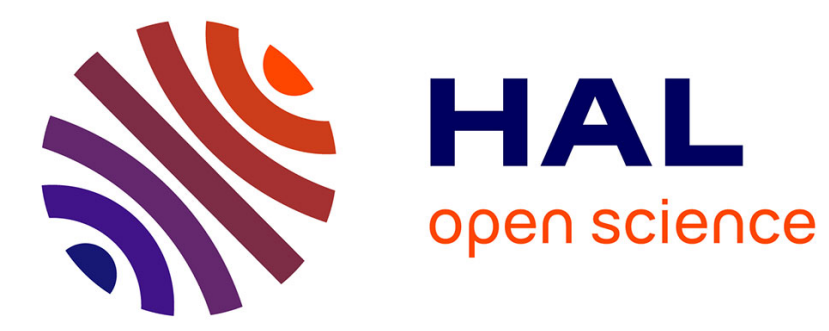

\title{
PROPERTIES OF HOT NUCLEAR MATTER
}

\author{
A. Lejeune, J. Cugnon, P. Grange
}

\section{To cite this version:}

A. Lejeune, J. Cugnon, P. Grange. PROPERTIES OF HOT NUCLEAR MATTER. International Conference On Heavy Ion Nuclear Collisions In The Fermi Energy Domain,Hicofed 86, 1986, Caen, France. pp.C4-373-C4-376, 10.1051/jphyscol:1986442 . jpa-00225808

\section{HAL Id: jpa-00225808 https://hal.science/jpa-00225808}

Submitted on 1 Jan 1986

HAL is a multi-disciplinary open access archive for the deposit and dissemination of scientific research documents, whether they are published or not. The documents may come from teaching and research institutions in France or abroad, or from public or private research centers.
L'archive ouverte pluridisciplinaire HAL, est destinée au dépôt et à la diffusion de documents scientifiques de niveau recherche, publiés ou non, émanant des établissements d'enseignement et de recherche français ou étrangers, des laboratoires publics ou privés. 
PROPERTIES OF HOT NUCLEAR MATTER(1)

\author{
A. IEJEUNE, J. CUGNON and P. GRANGE* \\ Université de Liège, Physique Nucléaire Théorique, Institut de \\ Physique au sart Tilman, Bâtiment B.5. B-4000 Liège 1, Belgium \\ "Centre de Recherche Nucléaire, BP 20, F-67037 strasbourg \\ Cedex, France
}

\begin{abstract}
Résumó - Les propriétés de la matière nucléaire froide et chaude sont étudiées dans le cadre de la théorie de Brueckner étendue aux températures finies. Nous nous limitons à l'approximation BHF. L'interaction choisie est le potentiel de Paris complété par une force à trois corps dérivée de l'échange de mésons $\pi$ et $\rho$. Une attention toute particulière a été apportée aux propriétés à un corps telles que le spectre des énergies à une particule, la masse effective et le libre parcours moyen. En relation avec le calcul de l'entropie, nous avons procédé à une évaluation du paramètre densité de niveau a et nous commentons la valeur obtenue. Enfin, l'influence de la température et de la densité sur une propriété à deux corps, à savoir l'interaction effective, fait'l'objet d'une première évaluation.
\end{abstract}

Abstract - The properties of cold and hot nuclear matter are studied in the frame of the Brueckner theory, extended to finite temperature. We limit ourself to the BHF approximation. The basic ingredient is the Paris potential supplemented by the introduction of three-body forces coming from the exchange of $\bar{J}$ and $\rho$ mesons. Particular attention is paid to one-body properties namely the single-particle energy spectrum, the effective mass and the mean free path. We evaluate and discuss the level density parameter a which is closely related to the calculated entropy. In a first approach, the temperature and density dependence of a two-body properties, the effective interaction, is analysed.

\title{
I - INTRODUCTION
}

The recent heavy ion experiments have given rise to an increasing interest in the properties of excited nuclei and of excited nuclear matter. In the course of such reaction, the matter is compressed and excited. Some important questions are raised, like : how to disentangle between the properties of the excited matter and the mechanism of the reaction, what is the equation of state of dense nuclear matter, what is the maximum excitation energy a nucleus can withstand,... ?

Some attempts to derive the general thermodynamical properties of nuclear matter from microscopic calculations have been done in the frame of the variational approach $/ 1 /$ or of the relativistic formalism $/ 2 /$. We want to use, here, a theory which has proven to be very fruitful in the past : the Brueckner theory. We use the continuous choice for the auxiliary potential $/ 3 /$. We report here on the single and two-particles properties.

\section{II - THEORETICAL FRAMEWORK /3,4/}

The central quantity is the second order term $B 82$ in the hole-line expansion in Brueckner theory and is given by

(1) Work supported by the WATO research grant $n^{*} 025.81$ 


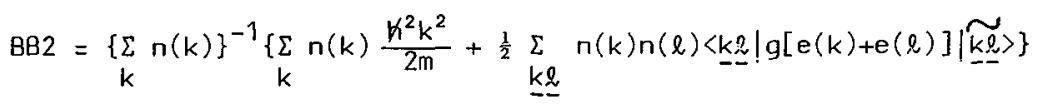

where $g$ is the Brueckner reaction matrix and $n(k)$ is the occupation probability for the level of momentum $k$ with value given by 1 or 0 at $T=0$ and by the following expression at finite $\mathrm{T}^{-}$

$$
n(k)=1 /\{1+\exp [e(k)-\mu) / T]\} .
$$

The single-particle energy $e(k)$ reads

$$
e(k)=\frac{k^{2} k^{2}}{2 \pi}+\operatorname{Re} u(k)
$$

with the s.p. average complex field defined by

$$
U(k)=\underset{\underline{j}}{\sum} n(j)\langle\underline{k} \underline{j}|g[e(k)+e(j)]| \underline{\underline{j} j}\rangle .
$$

At finite temperature, the evaluation of the partition function $z$ by mean of a perturbative expansion of a regular interaction can be found in many standard textbooks but for a singular interaction, the problem has not been very much studied. Nevertheless, it can be shown that up to the two-hole lines contribution, the general structure of the Brueckner theory is preserved after the proper modification of the occupation numbers $\mathrm{n}(\mathrm{k})$ (see eq. (2)). This approach allows the evaluation of the free energy, the entropy and the internal energy per particle $/ 4 /$.

\section{III - RESULTS}

We focuse ourself mainly on the single-particle properties. We recall that the quantity $U(k)$ is complex and can be identified to the well-known optical model potential. In Fig. 1 , Re $U(k)$ and Im $U(k)$ are displayed for several densities,

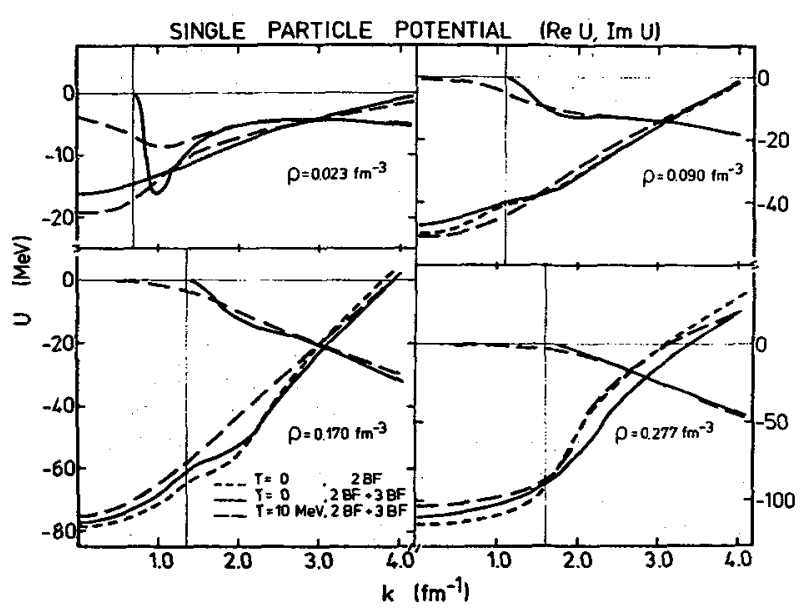

Fig. 1 - The single-particle complex field $U(k)$ versus the nucleon momentum $k$. both at $\mathrm{T}=0$ and $\mathrm{T}=10 \mathrm{MeV}$. At density between $0.17 \mathrm{fm}^{-3}$ and $0.33 \mathrm{fm}^{-3}$, the main effect of the temperature dependence is a reduction of the attractive mean field as the temperature increases. At small densities, the situation is a little bit different since an increase of the average potential takes place for low momentum. This results from a reduction of the attractive force and a strong reduction of the repulsive force. However, depending upon the situation, the reduction may be more effective for one part then for the other. As concern the imaginary part, the temperature dependence is the strongest at low density. The most noticeable feature is the non-vanishing values below the Fermi momen-

tum $k_{F}$. This comes from the partial occupation of levels below $k_{F}$, which makes real transitions possible.

Let us now turn to the effective mass $m^{*} / 3 /$. Fig. 2 shows the energy and temperature dependence. At $T=0$, three features are exhibited : the infinite slope at $k=k_{F}$, a peak somewhat above the Fermi level and a raising background underneath. The peak originates from the low lying core polarized states. As the 
temperature increases, the peak collapses rapidly, since the $1 p-1$ h core polarized states can be excited from any single-particle orbit. This is of great interest as concern the level density parameter $a$ which is related to $\mathrm{m}^{*}$ by the relation

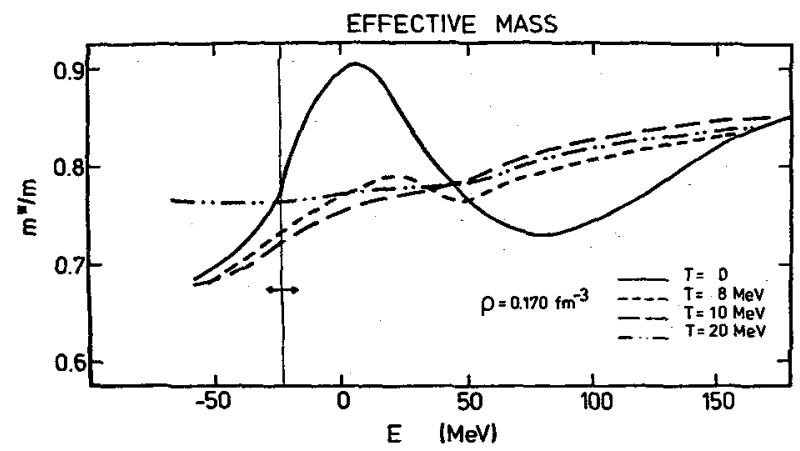

Fig. 2 - The nucleon effective mass $m^{*} / m$ versus the energy of the nucleon at normal density.

$a / A=1 / 3\left(\frac{m^{*}}{m} k m\right)_{k=k(\mu)}$.

We get the value $a \simeq 1 / 19 \mathrm{~A}$ which remains far from the empirical value $1 / 8 \mathrm{~A}$ (after taking into account the finite size effect). Nevertheless, eq. (5) opens interesting possibilities since the inclusion of the correlation effects produce a peak at the Fermi level with a value $m^{*} / m \simeq 1$. At this level of conjecture, a value of $1 / 14 \mathrm{~A}$ is obtained, in agreement with the empirical value. Fig. 3 displays the nuclear matter mean free path $\lambda_{\mathrm{nm}}$ at different densities and temperatures. The main feature

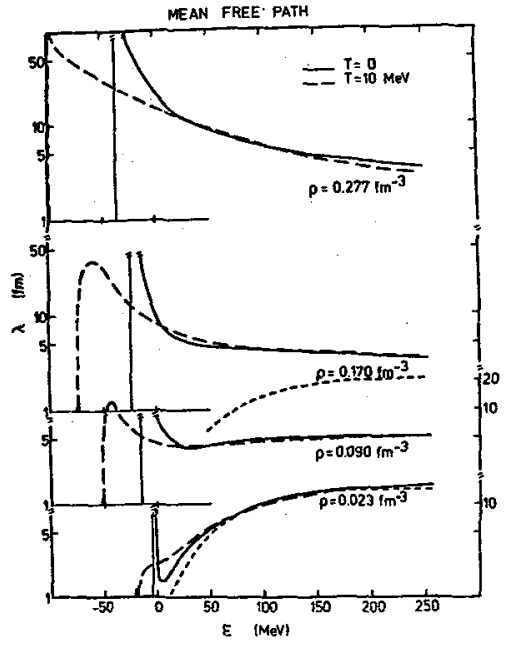

Fig. 3 - The nucleon mean free path $\lambda_{\mathrm{nm}}$ and the classical $\lambda$ (small dashed curve) versus the nucleon energy. is the finite value of $\lambda_{\mathrm{nm}}$ at the Fermi level for finite $T$. The decrease of $\lambda_{\mathrm{nm}}$ for increasing temperature helps to thermalize the nuclear system during heavy ion collisions at intermediate energies. At higher energy, the deviation from the

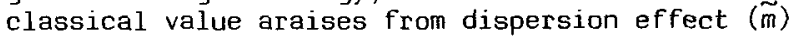
and from the Pauli principle through $g$.

Our calculations are the corner stone in order to construct an effective interaction veff. The structure of the latter will depend, of course, of the ansatz we make but we can get a rough idea of the $T$ and $\rho$ dependence by evaluating the ratio

$$
\alpha(k)=|g|^{2} /|\tau|^{2}
$$

after averaging over all the degrees of freedom but the relative momentum $k$. The result is shown on Fig. 4. The renormalization is very important in the 30-100 MeV range and should strongly influence the equilibration process in heavy ion collisions. The temperature dependence is weak for the two largest densities (not shown on the figure).

\section{REFERENCES}

11/ Friedman, B. and Pandharipande, V.R., Nucl. Phys. A361 (1981) 502.

/2/ Machleidt, R. and Brockmann, R., Phys. Lett. 160B (1985) 364.

/3/ Jeukenne, J.-P., Lejeune, A. and Mahaux, C., Phys. Rep. $25 \mathrm{C}$ (1976) 85.

/4/ Lejeune, A. Grangé, P., Martzolff, M. and Cugnon, J., Nucl. Phys. A453 (1986) 189. 


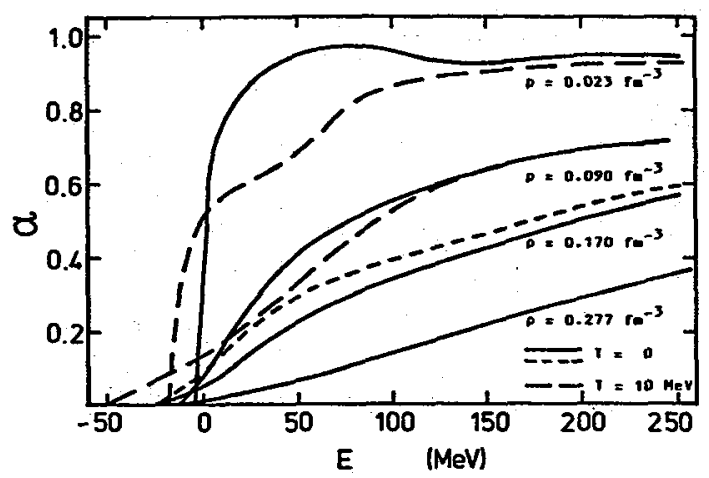

Fig. 4 - The coefficient $\alpha(k)$ (eq. (6)) versus the nucleon energy ( $T=0$ : full curves ; $\mathrm{T}=10 \mathrm{MeV}$ : long dashed curves). 